\title{
LOUISE BOURGEOIS
}

\section{LOUISE BOURGEOIS}

Pilar Muñoz López

Universidad Autónoma de Madrid

\section{Resumen:}

En este artículo se presentan unas breves notas sobre la vida y la evolución de la obra de la artista y escultora francesa Louise Bourgeois a partir de sus propios testimonios.

\section{Palabras claves:}

Louise Bourgeois, Cells, mujer.

\section{Abstract:}

In this article it is exposed some notes about the life and development of the work of the French artist and sculptor Louise Bourgeoise from her own testimonies.

\section{KEY WORD:}

Louise Bourgeois, Cells, woman. 
La biografía de Louise Bourgeois (1911-2010) es el fundamento sobre el que se apoya todo su proceso creativo, tanto en el arte como en la escritura. Ella misma declara en ocasiones que sus traumas y frustraciones infantiles sólo podían tener una curación posible: el arte, la escultura. En su obra Cell I (1991), en la que aparecen diversos utensilios domésticos (entre otros, una cama de hierro tenuemente iluminada, sobre la que reposan varios trozos de tela), en los fragmentos de tela ha bordado algunas frases: "El arte es la garantía de la cordura", "Necesito mis recuerdos: son mis documentos". Sobre esta obra dirá:

Las Cells representan distintos tipos de dolor: el dolor físico, emocional y psicológico, el mental y el intelectual. ¿Cómo se transforma lo emocional en físico? ¿Cuándo lo físico se vuelve emocional? Es una rueda que gira y gira. El dolor puede empezar en cualquier punto y desarrollarse en cualquier dirección. Cada una de las Cells versa sobre el miedo. El miedo es dolor, aunque con frecuencia no sea percibido corso do sor aul miedo. É miempre disfrazándose (..) Si el artista no

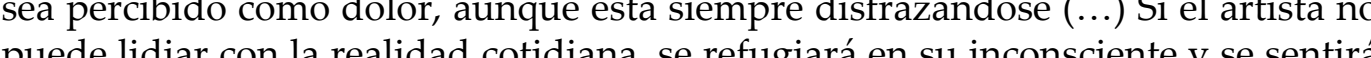
puede lidiar con la realidad cotidiana, se refugiará en su inconsciente y se sentira a gusto alli por muy limitado que sea y a veces incluso amenazante (...) La niña se ha hecho del inconsciente no un enemigo sino un refugio.

Por tanto, el arte tiene para ella un valor terapéutico, que cauteriza las heridas de su vida proyectando sus dolores y miedos en la obra plástica concebida por su mente y ejecutada con sus manos.

Nacida en 1911, ella misma nos informa de su biografía en una solicitud que realizó, a principios de los años 60, para continuar sus estudios de graduación en Bellas Artes en la Universidad de Nueva York:

Nací en París, Francia, y allí viví hasta que contraje matrimonio en 1938. Como mi marido era un profesor americano, resido desde entonces en Nueva York. Mis padres eran franceses y se ganaban la vida como restauradores de tapices antiguos, por tanto, desde niña había a mi alrededor un interés por el arte y por la historia del arte. Tenían cierta reputación, y nosotros -mis padres, mi hermana, mi hermano y yo- vivíamos en una casa espaciosa situada a las afueras de París. La elección de este lugar de residencia vino impuesta por las cualidades químicas del río Bièn de este lugar de reside pues sus aguas resultaban muy útiles, e incluso necesarias, para tenirir las lanas que usábamos en nuestros tapices. (...) Después de la guardería cursé mis estudios en el Lyceé Fenelon de París. Tras mi graduación entré en la Sorbona; esto es, doce años en una escuela de larga tradición y de una buena reputación escolástica. Como la salud de mi madre era delicada, consideró que yo debía ocupar su lugar en el trabajo en cuanto me fuera posible. Desde muy pronto me puso al corriente de los problemas del dibujo y del color y de los variados estilos de los tapices antiguos. También me enseño los problemas químicos vinculados a la búsqueda de tintes indelebles, con los que, en su opinión, debía trabajar de ahí en adelante. Por tales motivos mis padres me sacaron del colegio con quince años (dos años antes de la obtención del título de “Bachelot") aún cuando había sido la estudiante de honor de aquel curso acám "B. de aquel curso académico. Decidieron que necesitaba un aprendizaje profesional más intensivo, de modo que abandoné el Lyceé y trabajé en casa restaurando y
tejiendo tapices mientras recibía clases en París para preparar mi matriculación en la École de Beaux Arts. Conseguí mi título de "Baccalauréat" en la rama de Filosofía y para ello tomé clases de ética, lógica y psicología. (...) Por otra parte, estudié también Historia del Arte en la Ecole du Louvre como preparación para trabajar en el Museo del Louvre. Tras completar este curso, me convertí en docente del Louvre, y estaba empleada allí cuando, en 1938, conocí a mi futuro marido, que preparaba en aque que preparaba en aquel entonces su doctorado en Historia del Arte. (...) Vine a vivir a Nueva York en septiebre de 1938. En Nueva Yonte artístico floreciente. En este entorno nació mi deseo de conseguir una reputación como artista.

\section{Finalmente, concluirá su solicitud añadiendo:}

En los últimos años he comenzado a interesarme cada vez más por la psicología del arte debido a las reflexiones que he realizado sobre mis problemas como artista y a las conversaciones con otros artistas, y es por esto por lo que deseo reanudar mi aprendizaje

Pero la fría información expuesta en una solicitud académica no revela la biografía auténtica. Hay en el devenir del tiempo y en la sucesión de los acontecimientos biográficos un sustrato más real si cabe que se organiza y estructura en torno a las experiencias vividas, los sentimientos y las emociones que acompañan a las situaciones y vivencias desde el yo interior de cada persona. Esta es la base de nuestra evolución como individuos, de las decisiones que tomamos y del rumbo que trazamos a nuestra vida. Y esta biografía íntima está en el origen del trabajo creativo de Luoise Bourgeois.

Cuando tenía once años fue testigo de cómo su padre sustituía a su madre en la cama por Sadie Gordon, una joven inglesa a la que había contratado para cuidar y enseñan inglés a los niños. El impacto emocional de este suceso, que perduró durante diez años, la jactancia de su padre que se burlaba de ella continuamente, y la traición a su madre a la que adoraba, fueron el desencadenante de su actividad artística:

Me sentí atraída por el arte porque me aislaba de las difíciles conversaciones de la mesa donde mi padre se jactaba de lo bueno y maravilloso que era (...). Cogí un pedazo de pan blanco, lo mezclé con saliva y moldeé una figura de mi padre. Cuando estaba hecha la figura, empecé a amputarle los miembros con un cuchillo. Considero esto como mi primera solución escultórica. Fue apropiada para el momento y me ayudó. Fue una importante experiencia y determinó ciertamente mi dirección futura. En 1932, al mismo tiempo que se licenciaba en sus estudios universitarios, se
produjo el fallecimiento de su madre. En 1937 conoció a Robert Goldwater, profesor de historia del arte e investigador pionero en el estudio del arte primitivo, y en 1938 se casaron, como ella rememora en las líneas biográficas de su solicitud y en 1938 se casaron, como ella rememora en las líneas biográficas de su solicitud procrear, adoptaron a un niño francés, Michel. Pero en 1940 y 1941 tuvo dos hijos, Jean-Louis y Alain. Realizó su primera exposición individual en 1945 en 
la prestigiosa Galería Bertha Schaefer de Nueva York y posteriormente participo en dos exposiciones colectivas en el Museo Whitney de Arte Americano y en la Galería de Peggy Guggenheim, en la línea estilística del Expresionismo Abstracto.

Dedicada a la pintura, el dibujo y el grabado hasta finales de los años 40, en 194647 realiza varias pinturas y grabados titulados "Femme-Maison" en los que figuras femeninas y arquitecturas se integran en unidades compactas y en las que la artista reflexiona sobre la identificación entre mujer y casa. Esta interpretación ha hecho que se leyeran en clave feminista como un alegato contra el confinamiento tradicional de las mujeres en el ámbito doméstico. Sin embargo, otras interpretaciones enfatizan en la ambigüedad de la propuesta visual y en la idea de relación entre el espacio doméstico y la infancia, dentro de la actividad artística autobiográfica de la autora. En cualquier caso, dentro de una lectura artística, las "Femme-Maison" inauguran, con la fusión de cuerpo y arquitectura, la serie de oposiciones de las obras de Bourgeois (lo rígido y lo orgánico, lo geométrico y lo fluido, lo sólido y lo frágil), que surgirán en obras posteriores.

En los años 80, casi cuarenta años después, reanuda el tema de la "Femme-Maison" en versión escultórica. En sus esculturas de este periodo de nuevo encontramos las oposiciones que identificaban las primeras "Femme-Maison": el cuerpo frente a la arquitectura, lo rígido y geométrico de las arquitecturas y las formas orgánicas. Sobre esta temática dirá:

En aquellos días sólo lo sentía, pero ahora lo entiendo claramente. Si usted pregunta a una persona "¿es usted hombre o mujer?", ¿qué debería responder? ¿Debería simplemente morirse de vergüenza por el hecho de que algo tan íntimo de su persona hubiera sido revelado a todo el mundo? La mujer que dibujaba en aquella época -la femme maison- no tenía el aplomo y la objetividad para decir, sencillamente. "No me hagas ese tipo de preguntas". No. Ella huía y se escondía. (...) Para entender el tono de mi obra se podría mencionar como una característica general que soy masoquista. No sé si ésta es la actitud general de las mujeres o ge. De cualquier modo cua ho hie Fenmes Maisons (a principios de los ochenta) no. De cualquier esta tendencia masoquista se manifestó mediante dos sentimientos: pensaba que no tenia derecho a tener hijos ni a ser una artista, ya que ambas circunstancias me parecían dos privilegios que, en tanto que privilegio, por definición no merecía. Esto sucede continuamente; siempre estamos negándonos cosas: nuestra sexualidad, las herramientas necesarias para un artista -ya que ser escultor es caro-. Si consideramos el arte como un privilegio, en lugar de algo de utilidad para la sociedad, uno ha de sufrir y ahorrar por su arte, por aquello que ama; debemos negarnos a nosotras mismas en nombre del arte. Yo pensaba que era mejor ahorrar el dinero de mi marido antes que emplearlo en hacer esculturas.

El discurrir mental de Louise divaga continuamente sobre las mismas cuestiones, que son las que la hacen surgir como persona y como artista. En 1949 realiza una exposición en la Peridot Gallery, que titula The Blind Leading the Blind, y que hace referencia a una parábola de Jesús, mencionada en el Evangelio de San Lucas, en la que pregunta "¿Acaso puede un ciego guiar a otro ciego?". La obra está compuesta por dos barras paralelas de las que surgen perpendicularmente otras barras negras, rojas y rosas. El significado alude de nuevo a su infancia. Por un lado, al recuerdo de observar desde debajo de la mesa del comedor, las piernas de sus padres y la sensación de desprotección y exclusión del mundo de los adultos. Por otro lado, de nuevo surge el trauma de la infancia y las vivencias infantiles:

La ceguera provenía del sonrojo que experimentaba a causa de los que me rodeaban, de todos ellos. Como ya he dicho, mi padre era un promiscuo. Tenía que mostrarme ciega frente a su amante que vivía con nosotros. Tenía que mostrarme ciega frente al dolor de mi madre. Tenía que mostrarme ciega frente al hecho de que yo misma era un poco sádica con mi hermano. Tenía que mostrarme ciega ante la evidencia de que mi hermana se acostaba con el vecino de enfrente.

Las "piernas" de la escultura, no obstante su fragilidad y vulnerabilidad, parecen sostenerse y equilibrarse mutuamente, ya que "como no ven se agarran los unos a los otros", lo cual denota un atisbo de solidaridad humana que se hará más evidente en su siguiente exposición también en la Peridot Gallery (1949), en la que expone postes de madera pintada de aspecto totémico, y que evocan a aquellos amigos y familiares que fue dejando atrás. Con sus esculturas trata de conjurar la soledad que le provoca la ausencia de los seres queridos. Según cuenta ella misma:

Cuando los hombres se iban, me sumía en el caos total, es decir, en la soledad, una soledad espantosa. Hasta que me di cuenta de que podía ejercer un control sobre otra forma de expresion sobre otro mundo. Podía crear esas formas, pintartas de negro, lo que expresaba la tristeza. Podía colocarlas juntas, tirarlas al sula de negro, lo que expresaba la tristeza. Podía colocarlas juntas, tirarlas al suelo y destruirlas. Ese sentiniento de poder mestalgia que tenía de Francia. La excultra mesión gracias a una botella de leche, gracias a la forma triangular de un objeto útil, indispensable. Eso quería decir que era posible expresar algo

El espacio existente entre las diferentes formas es importante. En ocasiones se acercan o se unen de dos en dos; otras veces permanecen aisladas o bien se relacionan formando densas agrupaciones:

Son tan delicadas como las propias relaciones humanas. Se miran las unas a las otras y se sostienen mutuamente.

En los años 50 realiza esculturas elaboradas con fragmentos de madera, yeso, corcho y materiales diversos ensartados en barras de metal y que adoptan formas en espiral. La realización de estas esculturas coincide con un periodo de aislamiento en el que trabaja en su obra sin que vuelva a realizar ninguna exposición hasta 1964. Sobre su recurrencia a la espiral escribirá: 
La espiral es un intento de controlar el caos. Tiene dos direcciones ¿Dónde te situas, en la periferia o en el vortice? Empezando por el exterior está el miedo a perder el control; las vueltas cada vez son más estrechas, una retirada, un proceso de presión encaminado hacia la desaparición. Empezar en el centro es la afirmación, pues el movimiento hacia el exterior es una representación del acto de dar, de pus ceder espirales abierto. El miedo hace que el mundo siga girando.

En 1964 realiza una exposición en la Stable Gallery de Nueva York, en la que expone obras realizadas en materiales blandos y maleables, en oposición a sus obras anteriores en madera. En estas obras vuelven a resurgir los temas tratados con anterioridad y que constituyen el entramado de su devenir mental y creativo. Así, de nuevo, el tema de la casa y de la mujer, la madre y el padre, vuelven a surgir en las Lairs (Guaridas), lugares en los que protegerse, como la titulada Fée coutourière(Hada costurera) que hace referencia a la madre, que representa el calor y la protección, y cuyos cavernosos interiores se asemejan al vientre materno. Por el contrario, aquellas que simbolizan al padre constituyen lugares carcelarios y claustrofóbicos. En 1966 participó en una exposición fundamental en el devenir artístico norteamericano, Eccentric Abstraction, organizada por Lucy Lippard en la Fischbach Gallery de Nueva York, en la que surgía una nueva corriente escultórica opuesta a la estética minimalista, y en la que los críticos destacaron el aspecto orgánico y visceral de sus Lairs. Posteriormente, en 1967, evoluciona hacia formas bulbosas, montículos, cavernas, valles y agujeros, de ambiguo significado sexual que remiten a lo corporal, realizados en látex, caucho o alabastro. Sobre su referencia a lo corporal dirá: “Me parece evidente que nuestro cuerpo es una figuración que aparece en la Madre Tierra".

Entre 1967 y1968 trabaja en una serie de esculturas en las que, según los críticos, domina un carácter abiertamente erótico. Son los "falos dobles", como Janus fleuri, realizados en bronce y colgados del techo. La tersura de los dos falos colocados en los extremos contrasta con la rugosa parte central que se asemeja al sexo femenino:

Pasemos, por tanto, a esta escultura en particular. Ésta posee la permanencia de bronce, aunque fue concebida en escayola. Queda suspendida, es simple en su perfil, pero elusiva y ambivalente en sus referencias. Pendida de un solo punto al nivel de la vista, puede tanto balancearse como girar, aunque lentamente, ya que su nivel pere vista pu centro de gravedad es bajo. Es simétrica, como el cuerpo humano, y se presenta en la misma escala dín una doble máscara facial, dos pechos, dos rodillas. Su posición suspendida indica pasividad, si bien el hecho de que sea una masa suspendida a baja altura expresa resistencia y duración. Probablemente se trate de un autorretrato -uno de tantos.

En 1968 realiza Fillette (Chiquilla), en la que de nuevo aflora la ambivalencia entre lo masculino y lo femenino. Se trata de un gran pene de látex colgado del techo. El título, sin embargo, le confiere una cualidad femenina e infantil que contrasta con la obra. En 1982 el MOMA encargo a Robert Mapplethorpe realizar una fotografía de Bourgeois como reclamo a la retrospectiva que iba a realizarse de su obra. En ella aparecía sonriente llevando esta obra. Los responsables del MOMA, sin embargo, decidieron censurar la fotografía, haciendo desaparecer el enorme falo que la artista llevaba bajo el brazo. Christiane Terrisse sugiere que tras la conocida fotografía se esconde un guiño humorístico de la artista al psicoanálisis, a la "envidia del pene" que Freud atribuía a las mujeres:

En la imagen de Mapperthope, Bougeois toma al psiquiatra vienés al pie de la letra, en una representación literal del escenario freudiano: corroída (suponemos) por la envidia, la artista ha conseguido apoderarse del ansiado trofeo (El Órgano) y lo lleva bajo el brazo como si fuera un paraguas, una muñeca o un bolso. El Falo domesticado, apaciguado, convertido en un juguetito o, lo que es peor, en una niña...

En 1969-70 realiza una serie de obras de "mujeres fálicas", como Fragile Goddess (Diosa frágil), una especie de ídolo primitivo de grandes pechos y vientre, y cabeza en forma de cuchillo, o Femme-couteau (Mujer cuchillo), una hoja de cuchillo de mármol, en cuyo centro podemos observar formas protuberantes que pueden ser interpretadas como senos, nalgas o hendidura vaginal, o Femme-pieu (Mujer estaca), de pechos protuberantes y con la cabeza similar a una estaca erizada de pinchos de metal. Nos remiten a las diosas-madre prehistóricas, aunque en estas obras se transforman en objetos agresivos, sugiriendo la intercambiabilidad de los roles sexuales como constructos culturales:

En mi obra siempre han existido sugerencias sexuales. A veces mi preocupación se centra en las formas femeninas -racimos de pechos como nubes-, pero a menudo fusiono la imaginería -pechos fálicos, masculino y femenino, activo y pasivoEsta escultura de mármol-Mi Femme couteau- engloba la polaridad de la mujer, lo destructivo y lo seductor. ¿Por qué las mujeres se convierten en mujeres cuchillo? No nacieron como tales. Se les hizo así a través del miedo. En Femme couteau la mujer se convierte en un cuchillo, en una figura defensiva. Para defenderse se identifica con el pene. Una chica puede sentirse aterrorizada por el mundo. Sentirse vulnerable, ya que puede ser herida por el pene, de modo que trata de tomar la misma arma del agresor. Este es un problema que parte de la infania y de la infancia y de la falta de una educación razonable y conpreniva. (...) Es importante mostrar a las chicas que ser sexuas algo nutirse desamparados y vulnerables. (...) De algún modo, todos somos vulnerables, y todos somos masculino-femenino.

En los años finales de los 60 y en los 70 Bourgeois participa de la politización general de la sociedad norteamericana que protestaba contra la Guerra del Vietnam y luchaba por los derechos civiles de los negros, mientras surgía el Movimiento de Liberación de la Mujer. En 1971 participó en el "Forum: Women in Art", organizado por Cindy 
Namser, y en 1972 intervino, junto a diversas artistas y teoricas feministas, en una mesa redonda sobre el tema "Does Art Have a Gender?" ("¿Tiene el arte género?") celebrada en el YMCA de Nueva York. Sobre esta cuestión escribe:

La necesidad interior del artista de ser un artista conecta íntimamente con su género y su sexualidad. La frustración de la mujer artista y su falta de un papel inmediato de artista dentro de la sociedad es consecuencia de esta necesidad, y su impotencia (incluso si llega a tener éxito) es consecuencia de esta necesaria vocación. No elegimos nuestros papeles -obedecemos la llamada y aceptamos sus términos-, aunque ello no significa que no nos produzca resentimiento, por supuesto. E problema no está completamente claro; nos convertimos en escultores, digamos, a causa de nuestra incapacidad para madurar (y ésta es una bendición disfrazada) pero es un hecho que durante el resto de la vida seguimos siendo unos mendigos. asumirlo con dignidad.

La creación personal de Bourgeois, su forma de dar significado artístico a los miedos, fantasías secretas y deseos de las mujeres, y su constante introspección y exploración del pasado, constituyeron un atrayente modo de creación para el Movimiento Feminista, que otorgó a su obra un carácter político, ya que toda su producción está atravesada por esa conciencia de la diferencia sexual, por la polaridad Padre-Madre, que surge continuamente en sus creaciones. Fue en estos círculos feministas donde su figura y su obra comenzaron a tener visibilidad antes de su reconocimiento internacional.

En 1973 murió su marido, Robert Goldwater. Sobre él dijo que nunca la engañó y fue paciente con ella, ayudándola y apoyándola durante todo su matrimonio. Tras esto, impartió clases en la Escuela de Artes Visuales de Nueva York, la Universidad de Columbia, Cooper Union, Nueva York Studio School y la Universidad de Yale, mientras su reputación iba en constante aumento.

En 1974 realiza una instalación que se expone por primera vez en el 112 de Greene Street y que titula The Destruction of the Father (The Evening Meal) (La Destrucción del padre (La Cena), una especie de gran gruta iluminada con una intensa luz roja El techo y el suelo aparecen surcados por protuberancias bulbosas semejantes a las que conformaban los Lairs, y que asociamos a senos, nalgas, vientres... En el centro, una especie de mesa sobre la que reposan formas que recuerdan a vísceras y órganos humanos. Louise de nuevo regresa a las escenas familiares del pasado:

La finalidad de The Destruction of the Father era exorcizar el miedo. Después de que la obra se expusiera -ahí está- me sentí una persona distinta. No quisiera que la ora se expusiera -ahi está me senti una persona distinta. No quisiera utilizar la palabra "therapeutique", aunque todo exorcismo tiene un componente terapéutico. De modo que la razón que me llevó a hacer la obra era la catarsis o purificación. Cuando era pequeña, me daba miedo cuando estaba en a la mesa del comedor y mi padre no dejaba de alardear de su persona, se jactaba una y otra vez de sus logros, y cuanto más grande pretendía hacer su figura, más diminutos nos hacía sentir al resto. De repente, se producía una tensión máxima, terrible, y lo agarrábamos -mi hermano, mi hermana, mi madre y yo-, y los cuatro lo agarrábamos y lo colocábamos encima de la mesa y le arrancábamos los brazos y las piernas: lo desmembrábamos. Y éramos tan eficaces en esta labor que acabábamos devorándolo. Asunto terminado. Ésta es una fantasía cierto, pero a veces vivimos nuestras propias fantasías. Con The Destruction of the Father a veces vivimos el recuerdo que evocaba era tan poderoso, y tan duro el trabajo de proyectarlo hacia si efectivamente hubiese sucedido. Realmente me transformó.

El tema de la obra ha llevado a diferentes autores a una interpretación psicoanalítica, y así, entre otros, Bernadac ha indicado que no es casual que la obra haya sido realizada tras la muerte de su marido. La artista realiza este acto de exorzización, este banquete ritual, para deshacerse de la poderosa imagen del padre, de los padres, es decir, de las figuras de autoridad masculinas. En Confrontation (Enfrentamiento) (1978), una instalación presentada en la Hamilton Gallery of Contemporary Art de Nueva York una serie de cajas blancas en forma de ataúd rodean circularmente a una mesa centra en la que reposan formas globulares de látex similares a las de Destruction of the Father. Pero tras la explosión emocional que supusieron estas obras, la artista se serena y sus siguientes trabajos, ya a finales de los 70, regresa a formas geométricas y retoma el tema de la mujer. En 1978, Maisons fragiles (Casas frágiles) y Empty Houses (Casas vacías), dos instalaciones expuestas en la Galería Fourcade de Nueva York, muestran planchas de acero apoyadas sobre finas "piernas", y que parecen acercarse unas a las otras en un gesto de solidaridad. Estas "casas vacías" representan para ella la naturaleza interior de las mujeres, su fuerza y su vulnerabilidad, y al mismo tiempo, su capacidad de resistencia. En Partial Recall (Recuerdo parcial) (1979) un ensamblaje de postes de madera y semicírculos de diversos tamaños nos recuerdan la solemnidad de un altar:

En el polo opuesto, hay otras obras de naturaleza más pacífica y serena. Tras una emoción tan intensa representan una búsqueda, si no de paz, si de perdón u olvido. Es una súplica de paz, nada más... paz con uno mismo. En Partial Recall las piezas han encajado en su sitio -las cosas están como deben, les comptes son réglés-, a venganza se ha cobrado su parte y la justicia reaparece. El perdón y la clemencia están bien, pero no dejan de ser un refinamiento.

A lo largo de los años 80 realiza una serie de esculturas en las que recrea fragmentos del cuerpo humano:

Dado que los miedos del pasado se hallaban conectados a funciones del cuerpo, reaparecen a través de el.

Así, en Nature Study (Estudio del natural) (1984) realiza una síntesis de elementos corporales diversos en una figura humana y animal al mismo tiempo: tiene genitales 
masculinos pero pechos femeninos, y carece de cabeza. Según su propia interpretación sería una representación de su padre:

Puesto que mi padre me destrozó, ¿por qué no habría yo de destrozarle a él? Cojo un animal auténticamente masculino y para mofarme de él le pongo unos pechos y después de haberle puesto un par de pechos, le añado un segundo par, ¿por qué no? Y luego le corto la cabeza. Es una forma de burla. Puesto que se ha reído de mí, voy a reírme de él.

En 1985 realiza She-Fox (Zorra), una escultura de aspecto parecido a Nature Study entre humana y animal. Sobre ella nos dirá:

\begin{abstract}
La última obra se llama She-Fox. Es una pieza de $179 \mathrm{~cm}$. de altura de mármo negro. Representa a un animal, que es sin duda una hembra, pero no una hembra negro. Representa a un anis de los cuales es más grande y duro que el anterior -pero, de cualquier modo, los animales poseen numerosos pechos- y está sentada en cuclillas. Posee unos bellos muslos, unas patas sólidas y fuertes y una preciosa cola con un pequeño penacho en el extremo Tiene un gran corte en la garganta y le han sesgado la cabeza: una doble mutilación Por lo demás es perfecta. Muestra una gran dignidad y presencia mientras espera. Nada le molesta. La gente le hace cosas, pero ella las aguanta, es capaz de soportarlas, no le afecta aún estando mutilada. Bajo sus caderas hay una especie de refugio acogedor y allí es donde yo me coloco. Es como decir que coloqué ah la estatua llamada Fallen Woman (Mujer caída). Atendiendo al significado personal de la pieza, una expresión de la fe que un niño deposita en sus padres y de la de la pieza, una expresión de la fe que un niño deposita en sus padres y de la violencia que se establece entre el fuerte y el débil. Este es el significado de la obra. (...) En mi ha habitado un feroz sentimiento de amor maternal. Entendido de ese
modo-Fox sería también un autorretrato.
\end{abstract}

En 1982 el MOMA de Nueva York organizó la primera retrospectiva de su obra, y la segunda dedicada a una mujer. En 1983 fue nombrada Oficial de la Orden de las Artes y las Letras por el ministro francés de Cultura. En Europa, la primera exposición retrospectiva fue organizada por el Kunstverein de Frankfurt en 1989. También son los 80 el momento en que traslada sus obsesiones, especialmente la de la casa y la mujercasa, a un tamaño mucho mayor. Precedidas por una serie de esculturas que, de nuevo retoman el nombre de Femme-Maison y que, de nuevo muestran las contraposiciones orden-desorden, rígido-blando, geométrico-orgánico, amplía el tema de la casa a nivel arquitectónico, creando una serie de habitáculos en los que el espectador puede penetrar, y que desarrollará extraordinariamente en los 90 en sus Cells. En estas instalaciones de nuevo fluyen sus reflexiones sobre la temática del hogar doméstico y la mujer, y los títulos de algunas de ellas así lo revelan: No Exit (Sin salida) (1988), No Escape (Sin escapatoria) (1989), con escaleras fálicas que no conducen a ninguna parte, y donde lo público y lo privado se interrelacionan, y en las que diversos materiales (piedra, metal, telas...) nos ofrecen la sensación de vulnerabilidad y ambigüedad, entre el dentro y el fuera, entre lo masculino y lo femenino. Articulated Lairs es la primera de las "casas" que realiza a gran escala y en la que de nuevo se reencuentran las formas orgánicas con las rígidas y arquitectónicas. De nuevo el tema del hogar, del refugio, de la cueva al mismo tiempo que la celda opresiva. Ésta sería también la reflexión que se esconde tras las Cells de los años 90. Buorgeois dirá sobre ellas:"Todas las Cells tratan sobre el placer del voyeurismo, la excitación de mirar y ser mirado".

El cuerpo y las funciones y fluidos corporales es otro de sus temas de reflexión en los 90, y así lo atestigua su instalación Precious Liquids (Líquidos preciosos) realizada en 1992 para la IX Documenta de Kassel: en un enorme tonel, en el que el espectador puede entrar, podemos observar una cama de hierro en cuyo centro hay un pequeño charco de agua y en cuyas esquinas encontramos cuatro barras de metal en las que cuelgan diversos recipientes de vidrio. Según sus palabras, el vidrio es un símbolo de lo femenino, en lo que se unen resistencia y fragilidad. Frente a la cama se sitúan dos bolas de caucho y una escultura de alabastro; al otro lado, un perchero de madera del que cuelga un abrigo masculino, y en su interior se esconde un pequeño vestido de niña con las palabras bordadas "Merci/Mercy", jugando con el doble significado en francés e inglés "Gracias/Piedad":

Lo que está en juego aquí es el problema de las funciones corporales. Cuando estamos en tensión, nuestros músulos se contraen; cuando se relajen y la tensi desapas en un liquido un liquido promente en un liquido, un liquico pro de autoridad. El pequeño vestido que se refugia en el gran abrigo representa a la hija que ha sido sometida a fuertes emociones y ha sido capaz en su proceso de maduración de sentir piedad por el Gran Extravagante seductor.

En 1993 representó a Estados Unidos en la Bienal de Venecia con la obra Cell ( Arch of Hysteria): rodeado de una barrera de puertas metálicas, el espectador se ve obligado a adentrarse en un estrecho pasillo al final del cual aparece una cama en la que yace el cuerpo de un hombre sin brazos ni cabeza y arqueado de forma similar a las fotografías de mujeres histéricas de Charcot, en el hospital parisino de la Salpêtrière. En el archivo fotográfico de Charcot las pacientes son mujeres, mientras que en la versión de Buorgeois aparece un cuerpo masculino. Aparece también en la instalación una sierra mecánica y una sábana blanca en la que se lee repetidamente "Je t'aime". Si por un lado cuestiona la tradicional identificación entre histeria y mujer, así como la importancia de la diferencia sexual en el discurso médico, por otra parte entronca con algunos de los temas presentes en la obra de Bourgeois: la sexualidad, el sentimiento de culpa, el tabú del deseo o la fragmentación del cuerpo:

Este es el arco de la histeria, el placer y el dolor se mezclan en un estado de felicidad. El arco (el aumento y el relajamiento de la tensión) es sexual. Es un sustituto del orgasmo en alguien que no tiene acceso al sexo. 
A partir de 1992 comienza a introducir en sus obras agujas, bobinas, husos, tejidos y arañas, que evocan el ambiente familiar de su infancia, y que rememoran espacialmente la figura de su madre, pero que también nos llevan a las actividades femeninas, ignoradas o despreciadas en la historia:

En mi infancia, todas las mujeres utilizaban agujas. He sentido siempre fascinación por la aguja, por el poder mágico de la aguja. La aguja sirve para reparar daños. Es una demanda de perdón. No tiene nunca un carácter agresivo, no es un imperdible.

En 1994, la exposición “Louise Bourgeois: Locus de la Memoria" mostró esculturas y una serie de dibujos sobre el tema de la araña, que ella asociaba con su madre: dibujos, pequeñas o enormes esculturas, familias de arañas...

La amiga (la araña, ipor qué la araña?), porque mi mejor amiga era mi madre y porque era reflexiva, inteligente, paciente, reconfortante, razonable, refinada sutil, indispensable, limpia y útil como una araña (...) No me cansaré nunca de representarla.

Los cuerpos de sus enormes arañas funcionan como un refugio en el que cobijarse con lo que volvería de nuevo al tema de la "Femme-Maison". En 1994 presenta la instalación Red Rooms (Habitaciones rojas) en la Galería Peter Blum de Nueva York. De nuevo angostos pasillos que dan acceso a una habitación roja en cuyo centro una cama de matrimonio de color rojo, y en su centro un tren de juguete, la caja de un instrumento musical y dos almohadones bordados con letras rojas con la inscripción "Je t'aime". También aparece sobre la cama un dedo de goma atravesado por una aguja, y pende del techo un extraño objeto de aspecto orgánico. De nuevo, la amenaza lo siniestro, irrumpe en la paz del hogar familiar. En 1996, en su obra Couple (Pareja, cópula), en un ambiente sórdido encontramos, sobre un colchón central, un muñeco decapitado vestido con ropa masculina, que yace pesadamente sobre una muñeca sin cabeza con un collar de perlas que la identifica como mujer:

La pareja copulando es vista a través de los ojos de una niña pequeña. ¿Están peleándose? ¿Se lo están pasando bien? ¿Está intentando uno de ellos matar al otro? Hace referencia a una edad en la que yo no podía entender lo que estaban haciendo, lo que veían el uno en el otro, lo que esperaban encontrar en el otro. Se trata de la fijación de una experiencia traumática.

En la segunda mitad de los años 90 los tejidos, los ovillos, las agujas, los vestidos..., adquieren una importancia fundamental en la elaboración de sus obras. La ropa, como apunta Bernadac, se sitúa en esa frontera borrosa entre lo privado y lo público que ha preocupado a Bourgeois desde los comienzos de su aventura creativa. Del mismo modo, simultáneamente a su obra plástica ha desarrollado una escritura literaria consistente en la realización de un diario que comenzó a los doce años y que ha continuado escribiendo a lo largo de su vida; también ha realizado un diario a través del dibujo, con esbozos, anotaciones, impresiones, traducidos en trazos y líneas:

Tener varios diarios significa que me gusta tener mi casa en orden. Me resulta imprescindible llevarlos al día para asegurarme de que la vida no se me escapa.

En 2004 presentó en España, en el Centro de Arte Contemporáneo de Málaga, una selección de sus obras titulada Stitches in Time (Puntadas en el tiempo) en la que se mostraban algunas de sus Cells y obras gráficas relevantes de su trayectoria profesional. En una entrevista publicada en "El Cultural", del Diario "El Mundo", respondía así a una pregunta:

-Hace tiempo dijo usted que había querido ser artista para sentirse útil. Después de una larguísima trayectoria y con su conocimiento del mundo del arte, ¿Cree aun que un artista puede ser util?

Luouise Bourgeois: -Creo que los artistas podemos contribuir a muchas cosas. Yo hago lo que hago, y si la gente se siente "tocada" por lo que haces mucho mejor. Yo no soy ni una profesora ni una predicadora. No le debo nada a nadie pero los artistas tenemos ese acceso al inconsciente. Es una bendición y a la vez una maldición. De lo que tengo certeza es de que cuando estoy creando me siento mejor persona.

El 31 de mayo de 2010 falleció de un ataque al corazón. Desde los años 80 residió y trabajó en su casa de Chelsea y en su estudio de Brooklyn, junto a su asistente, Jerry Gorovoy. Le sobreviven dos hijos, Jean-Louis y Alain, dos nietos y una bisnieta. Su primer hijo, Michel, murió en 1990. Entre otras distinciones, obtuvo el Gran Premio Nacional de Escultura del Gobierno francés (1991), la Medalla Nacional de las Artes de Estados Unidos, entregada por el Presidente Bill Clinton (1997), el Premio a la Trayectoria del Centro Internacional de Escultura de Washington, o su elección como miembro de la Academia Americana de las Artes y las Ciencias.

\section{REFERENCIAS BIBLIOGRÁFICAS}

Bernadac, M.L., Louise Bourgeois, Flammarion, París, 1995

Bernadac, M.L. y Obrist, H.U., Louise Bourgeois. Destruction of the Father Reconstruction of the Father. Writings and Interviews, 1923-1997, Violette Editions, London, 1998

Bourgeois, L., Destrucción del padrel reconstrucción del padre. Escritos y entrevistas 19231997, Síntesis, Madrid, 2008

"El Cultural", Diario El Mundo, 28/05/2010

Mayayo, P., Louise Bourgeois, Nerea, Hondarribia (Guipuzcoa), 2002 
Meyer-Thoss, C., Konstruktionen für den freien Fall. Designing for Free Fall, Amman Verlag, Zurich, 1992

Wye, D., Louise Bourgeois, The Museum of Modern Art, Nueva York, 1982. 